\title{
Framework of behavioral indicators for outcome evaluation of TB health promotion: a Delphi study of TB suspects and Tb patients
}

\author{
Ying $\mathrm{Li}^{1^{*}}$, John Ehiri ${ }^{2 *}$, Daiyu Hu${ }^{3}$, Yanqi Zhang ${ }^{4}$, Qingya Wang ${ }^{3}$, Shun Zhang ${ }^{3}$ and Jia Cao ${ }^{5}$
}

\begin{abstract}
Background: Health promotion for prevention and control of Tuberculosis (TB) is implemented worldwide because of its importance, but few reports have evaluated its impact on behavior due to a lack of standard outcome indicators. The objective of this study was to establish a framework of behavioral indicators for outcome evaluation of TB health promotion among TB suspects and patients.
\end{abstract}

Methods: A two-round modified Delphi method involving sixteen TB control experts was used to establish a framework of behavioral indicators for outcome evaluation of TB health promotion targeted at TB suspects and patients.

Results: Sixteen of seventeen invited experts in TB control (authority score of 0.91 on a 1.0 scale) participated in round 1 survey. All sixteen experts also participated in a second round survey. After two rounds of surveys and several iterations among the experts, there was consensus on a framework of indicators for measuring outcomes of TB health promotion for TB suspects and patients. For TB suspects, the experts reached consensus on 2 domains ("Healthcare seeking behavior" and "Transmission prevention"), 3 subdomains ("Seeking care after onset of TB symptoms", "Pathways of seeking care" and "Interpersonal contact etiquette"), and 8 indicators (including among others, "Length of patient delay"). For TB patients, consensus was reached on 3 domains ("Adherence to treatment", "Healthy lifestyle" and "Transmission prevention"), 8 subdomains (including among others, "Adherence to their medication"), and 14 indicators (including "Percentage of patients who adhered to their medication"). Operational definitions and data sources were provided for each indicator.

Conclusions: The findings of this study provide the basis for debate among international experts on a framework for achieving global consensus on outcome indicators for TB health promotion interventions targeted at TB patients and suspects. Such consensus will help to increase effectiveness of TB health promotion, while ensuring international comparability of outcome data.

Keywords: Health promotion, Outcome evaluation, TB suspect, TB patient, Indicator

\section{Background}

Although significant progress has been made in global Tuberculosis (TB) control over the past decade, the disease remains an abiding global health challenge [1]. TB is transmitted primarily through the airborne route, and key control measures are early diagnosis and prompt treatment of

\footnotetext{
* Correspondence: lilyliying2012@163.com; jehiri@email.arizona.edu 'Department of Social Medicine and Health Service Management, Third Military Medical University, No.30 Gaotanyan Road, Shapingba district, Chongqing 400038, China

${ }^{2}$ Division of Health Promotion Sciences/Global Health Institute, Mel \& Enid Zuckerman College of Public Health, University of Arizona, Tucson, Arizona, USA Full list of author information is available at the end of the article
}

individuals with active disease, and identification and treatment of latent infections [2]. However, delays in diagnosis and treatment, and treatment failures resulting from low adherence are common in many low and middle income countries with high TB burdens [1,3-10]. There is considerable literature on individual and health systems factors that influence patient, diagnostic, and treatment delays $[8,11]$. Factors that contribute to poor adherence to TB treatment and prevention, and barrier in multi-drug resistant $\mathrm{TB}$ (MDR-TB) treatment have also been widely documented [12-14]. Many of the factors that contribute to TB proliferation are modifiable through health promotion, yet, ТB 
continues to present significant threats to health in high burden countries, and the emergence of multi-drug resistance continues to increase globally [1]. Health Promotion is defined as the process of enabling people to increase control over, and to improve their health [15]. TB health promotion includes individual empowerment, community empowerment, health systems strengthening, interagency partnerships, and intersectional collaboration [16]. For TB suspects and TB patients, health promotion would play a key role in improving TB knowledge and awareness, health seeking behavior, treatment adherence, and thus, treatment outcome [17-19].

Given the public health significance of TB, health promotion interventions to prevent and control the disease have been conducted, and continue to be conducted globally. In some cases, these interventions are aimed at strengthening people's understanding of the disease and how to respond to symptoms [20-24]. Such interventions have also been used to reduce TB stigma [18,19], a major cause of TB diagnostic and treatment delay and poor adherence to treatment $[11,17,21,25,26]$. Overall, these TB health promotion activities have sought to influence behavior change and encourage adherence to treatment [17] through multifaceted package of interventions [21,25,26]. Some countries, including China $[27,28]$ and New Zealand [16], have issued special guidelines for TB health promotion that specify TB health promotion activities targeting behavioral interventions for different populations groups [17]. Unfortunately, these guidelines lack appropriate indicators for assessment of outcomes. In the New Zealand guideline for example, measures of quality and effectiveness of TB health promotion and education are deficient [16]. In China, the 2008 Guideline on Enforcement of Chinese Tuberculosis Control Program describes only two evaluation indicators (rate of completion of health promotion activities, and TB core knowledge of target participants) [28]. Unfortunately, knowledge alone often does not translate to actual behavior changes [29-31].

Evaluation of health programs is important to assess the extent to which programs meet stated objectives [32]. Evaluation usually includes assessment of inputs, processes, outputs, outcomes, and impacts [32-34]. Outcome evaluation assesses the short and medium term effects of an intervention (e.g., behavior change or changes in health status) and correlates them with the program's objectives [34]. Having appropriate indicators for ascertaining achievement of program objectives is key to meaningful evaluation, and such indicators should be identified and determined in the initial stages of program planning [35,36]. Although other major diseases of global significance (including HIV/AIDS) have universally accepted framework of indicators for assessing the impact of health promotion activities [35,37], the global TB control effort has no such framework of indicators for its health promotion.
The only available framework for monitoring and evaluating national TB control programs was that issued by the World Health Organization in 2004 [38-40]. Unfortunately, this framework only covers outcome of detection and treatment, but neglects other important behavioral changes that may be associated with TB health promotion interventions. To facilitate the development of a universal framework of outcome indicators to guide TB health promotion interventions in countries with high TB burden, we conducted a study to establish behavioral indicators for outcome evaluation of individual level TB health promotion, using the Delphi method [41].

\section{Methods}

We used the Delphi method to establish the framework of indicators for individual level TB health promotion. The Delphi method is a consensus technique that collects expert opinions through several rounds of surveys or interviews. It has 4 distinguishing features: anonymity, iteration, controlled feedback, and statistical group response (expression of the degree of consensus within a group) [42-45]. From various Delphi methodologies [41], we chose the Modified Delphi method, which includes two quantitative rounds of surveys that were conducted from May to October 2012.

\section{Selection of Delphi experts}

The purposive sampling technique [46] was used to select informed individuals to serve in a panel of experts for the Delphi process. Expertise and eligibility were determined using the following criteria:

1) Policy maker at national or provincial level who had been working for at least 5 years in TB diagnosis, treatment, or prevention.

2) Senior TB professional with in-depth knowledgeable and experienced in TB control (including physicians directly involved in TB diagnosis and treatment).

3) National coverage - representation from eastern, western, northern, and southern China to ensure national generalizability of results.

A total of 17 TB control experts from national and provincial level TB control facilities participated in the Delphi process. During recruitment, potential experts were approached (initially via e-mail and later by telephone) and provided with detailed explanation of the study and its objectives. They were then asked if they would be interested in volunteering to participate. Those who expressed interest were asked to read the informed consent form, and were assured of confidentiality. They were sent an informed consent form to review, sign and return in an addressed stamped envelope as a conformation of their voluntary participation in the study. 
Ethical approval for the study was obtained from the Health Research Ethics Board of Third Military Medical University, China.

\section{Instrument}

The instrument for the Delphi surveys consisted of four parts:

1) instructions for the Delphi survey, used to introduce the study Domains and to clarify how to complete the survey;

2) questionnaire (main instrument) with indicators for evaluating the impact of individual level TB health promotion;

3) information about experts' authority in the field of TB control (familiarization with indicators and judgment criteria for the indicator), and
4) general information about the experts, such as (age, professional title, position, education, major, duration of work in the field of TB control).

The process of development of the main Delphi survey questionnaire is presented in Figure 1 (steps 1-3). First, we developed a detailed framework that was created based on an in-depth review of TB experts, information from previous studies [11,47-54], and review of relevant literature on TB control and TB health promotion $[17,28,55]$. Second, TB health professionals working in TB dispensaries were asked to comment on the draft instrument, and to add as appropriate, other indicators and operational definitions. This resulted in two draft questionnaires (domains, subdomains, and indicators) on TB health promotion, one for TB suspects and one for TB patients. Third, the questionnaires were pre-tested on a convenient

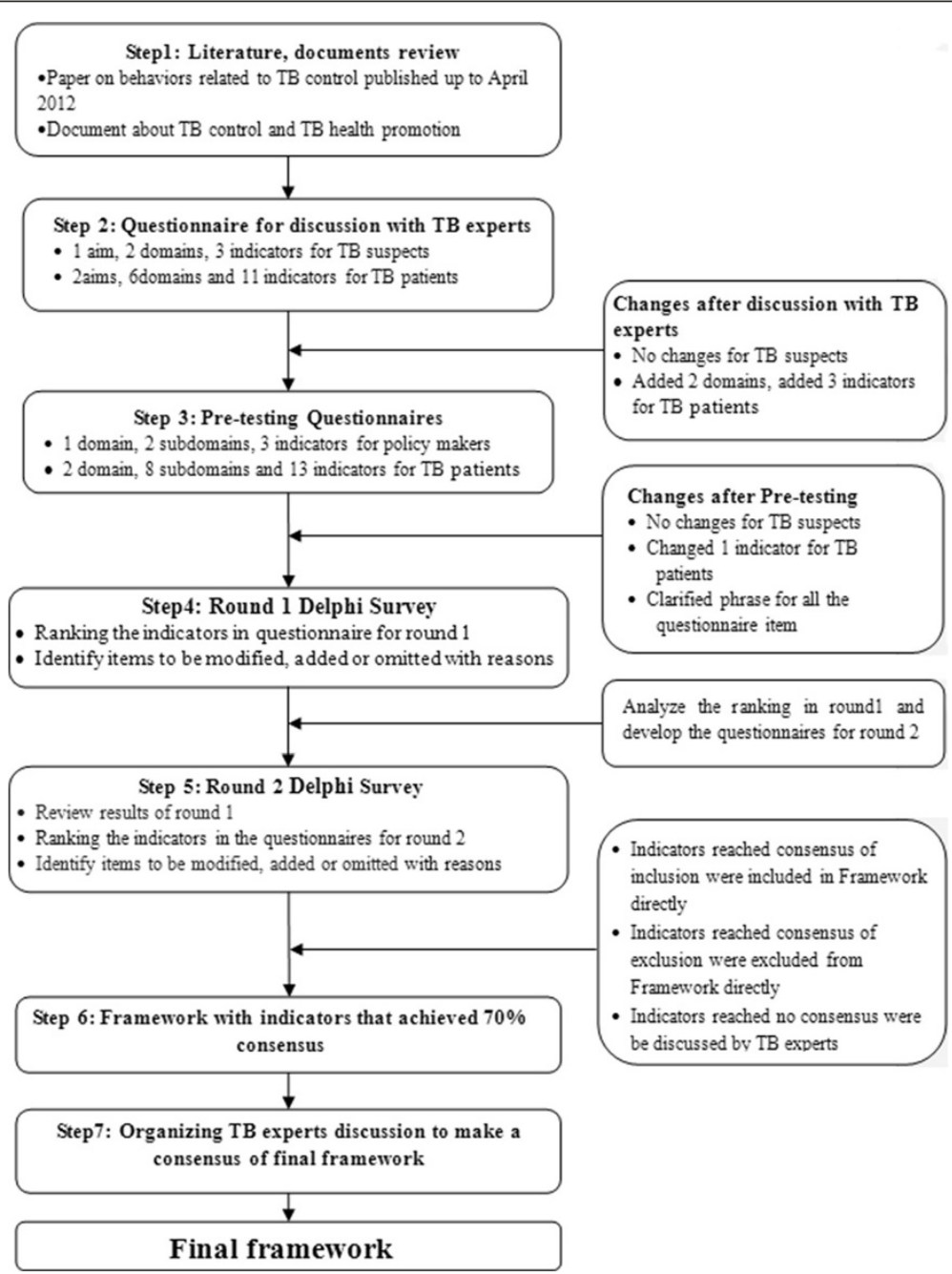

Figure 1 Flowchart of the Delphi survey questionnaire design and Delphi process. This figure describes the process in the development of main Delphi survey questionnaire (Steps 1-3) and the procedure used to implement the Delphi process (Steps 4-7). 
sample of 3 TB health workers who reviewed appropriateness and clarity of the questionnaire items. Fourth, as a result of pre-testing, proper phrasing was developed; respondents' interpretations were evaluated, and Delphi questionnaires were finalized and applied as the survey instruments used to obtain responses from experts. The Delphi survey questionnaire that addressed health promotion indicators for TB suspects included 1 domain, 2 subdomains, and 3 indicators. The survey instrument for TB patients included 2 domains, 8 subdomains, and 14 indicators (Additional file 1: Table S1). Both instruments included operational definitions of all the potentially relevant indicators. Experts were asked to assess the importance and feasibility of each indicator on a 5point Likert Scale in the following order and score: extremely unimportant/infeasible (1), unimportant/infeasible (3), somewhat important/feasible (5), important/feasible (7), and extremely important/feasible (9). Finally, the experts were given the options to delete, add, and modify indicators but were required to articulate the reasons behind their choices.

Information on experts' authority included levels of familiarity with the indicators (extremely familiar, very familiar, somewhat familiar, somewhat unfamiliar, very unfamiliar, extremely unfamiliar) and judgment criteria on these indicators (theory analysis, practical experience, literature review, intuition) [56]. General information about the experts included age, position, professional title, education, work area, and years of experience in TB control.

\section{Setting the consensus level}

The Delphi method is based on panelists' achieving consensus. However, expert opinions can differ, and it is difficult to gain $100 \%$ agreement on all issues. Therefore, a key question in Delphi studies is the percentage of agreement the researcher would accept as representing consensus [57]. However, no standard method or appropriate guidelines are available for determining consensus levels [57-60]. For this study and in line with other related studies [61-69], we set the consensus level at $70 \%$ as follows:

1) Consensus of inclusion: $>70 \%$ of participants scored the item $\geq 7$

2) Consensus of exclusion: $>70 \%$ subjects scored the item $\leq 5$;

3) No consensus: item failed to meet either of the above criteria.

\section{Procedures for the Delphi survey}

Figure 1 shows the flow of the Delphi process (Step 4-7). In the first round, participants were asked to rank the importance and feasibility of the indicators to evaluate

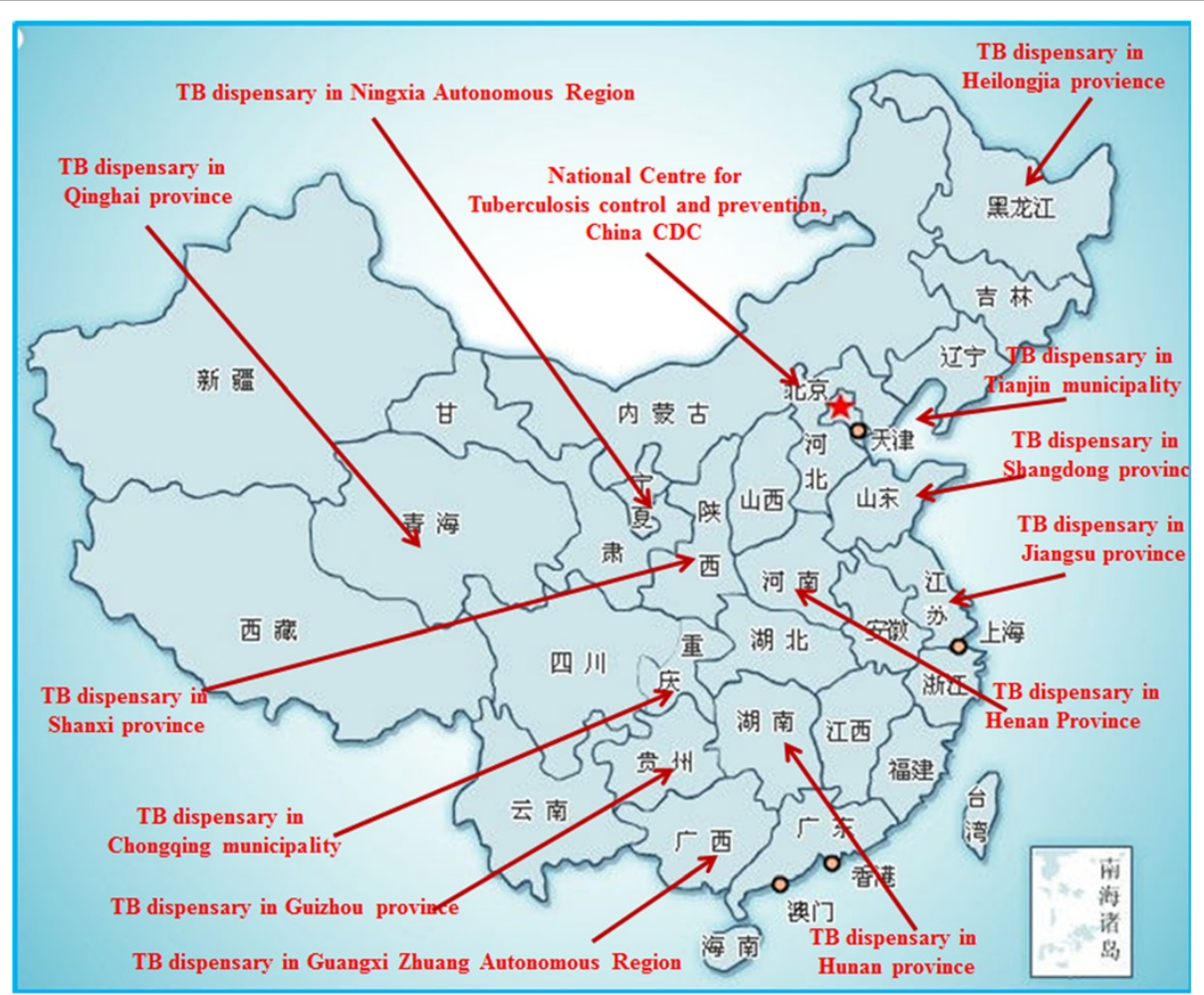

Figure 2 Experts in Delphi expert panel. This figure presents the geographic distribution of experts who participated in the Delphi expert panel. The sixteen experts were from thirteen provinces/regions representing North, South, East, and West, China. 
behavioral outcomes of individual level TB health promotion. The responses in the first-round survey were analyzed, using descriptive statistics, and the results were sent back to the experts for review and ratification. Items that achieved consensus of exclusion (i.e., $>70 \%$ of the experts scored the item $\leq 5$ ) in the first round survey were excluded from the questionnaire for second round survey. Items for which were recommended for modification by the experts were revised and added to the second round survey; new items suggested by the experts were also added to the second round survey. In the second survey, participants were asked to re-rank the consensus results from the first round. Second Delphi responses that reached $70 \%$ consensus were determined as appropriate items (domains, subdomains and indicators) for assessing behavioral outcomes of individual level TB health promotion. The final framework was presented to experts for discussion and final consensus, leading to the final framework.

\section{Statistical analysis}

Descriptive data analyses for the first and second round Delphi surveys were undertaken, using the Statistical Package for the Social Sciences (SPSS) version 18.0. The authority coefficient $\left(C_{r}\right)$ was used to assess the degree of the experts' authority in relation to their technical ability to evaluate the indicators as determined by two factors, the judgment criteria for the indicators $\left(C_{a}\right)$ (Additional file 1: Table S2) and the experts' familiarity with the indicators $\left(C_{\mathrm{s}}\right)$ (Additional file 1: Table S3) [56]. $\mathrm{C}_{\mathrm{r}}$ is defined as follows:

$$
C_{r}=\frac{C_{a}+C_{s}}{2}
$$

Median and mode were used to describe the central tendency of expert responses.

Coefficient of variation (CV) was used to describe the dispersals of expert responses. $\mathrm{CV}$ is the ratio of the standard deviation of the responses of the experts on a specific item to its corresponding mean (average). Therefore, the responses of the experts for each survey item in each round of the Delphi survey yielded one CV [70].

\section{Results}

\section{Characteristics of the experts}

During the first round Delphi survey, questionnaires were sent to seventeen experts, sixteen of whom responded. The sixteen experts who participated in the survey were from thirteen provinces/regions representing North, South, West, and East China (Figure 2). All sixteen experts who responded to the first round survey also completed the second round survey. Descriptive information about the experts is presented in Table 1. All the experts had 8 or more years of experience (ranging from 8 to 36; mean =
Table 1 Expert characteristics

\begin{tabular}{|c|c|c|}
\hline Characteristics & Number & Percentage \\
\hline \multicolumn{3}{|l|}{ Age } \\
\hline$<40$ & 1 & 6.3 \\
\hline $40-45$ & 3 & 18.8 \\
\hline $45-50$ & 9 & 56.3 \\
\hline$>50$ & 3 & 18.8 \\
\hline \multicolumn{3}{|c|}{ Years of experience in TB control } \\
\hline$\leq 10$ & 2 & 12.5 \\
\hline $11-20$ & 5 & 31.3 \\
\hline $21-30$ & 7 & 43.8 \\
\hline$>30$ & 2 & 12.5 \\
\hline \multicolumn{3}{|l|}{ Types of expertise } \\
\hline Policy makers & 3 & 18.8 \\
\hline Managers in TB dispensaries & 9 & 56.3 \\
\hline Staff in TB dispensaries & 5 & 31.3 \\
\hline \multicolumn{3}{|l|}{ Work unit } \\
\hline National level & 3 & 18.8 \\
\hline Province level & 13 & 81.3 \\
\hline \multicolumn{3}{|l|}{ Educational level } \\
\hline College & 2 & 12.5 \\
\hline University & 10 & 62.5 \\
\hline Graduate & 4 & 25.0 \\
\hline \multicolumn{3}{|l|}{ Professional title } \\
\hline Middle & 2 & 12.5 \\
\hline Associate senior & 5 & 31.3 \\
\hline Senior & 9 & 56.3 \\
\hline \multicolumn{3}{|c|}{ Response rates to questionnaires } \\
\hline Round 1 & 16 & 94.1 \\
\hline Round 2 & 16 & 100 \\
\hline
\end{tabular}

$11.9, \mathrm{SD}=5.1)$ as full-time professionals in TB control facilities. A majority $(n=12)$ had 11 to 30 years of experience.

\section{Experts' authority levels $(\mathrm{Cr})$}

The expert authority coefficient ranged from 0.91 to 0.92 , and the average $\mathrm{Cr}$ was 0.92 , which indicated that all 16 experts had high degree of authority in the area of

Table 2 Expert levels of authority

\begin{tabular}{cccc}
\hline Round & $\begin{array}{c}\text { Judgment } \\
\text { criterion }\left(\mathbf{C}_{\mathbf{a}}\right)\end{array}$ & Familiarity $\left(\mathbf{C}_{\mathbf{s}}\right)$ & Authority $\left(\mathbf{C}_{\mathbf{r}}\right)$ \\
\hline First round & 0.92 & 0.91 & 0.91 \\
Second round & 0.93 & 0.91 & 0.92 \\
Average & 0.92 & 0.91 & 0.92 \\
\hline
\end{tabular}


Table 3 Results of round- 1 survey

Items
TB suspects
Domain
Health-care seeking behavior
Subdomain
Care-seeking behavior at onset of TB symptoms
Care-seeking pathways

\section{Indicators}

Length of patient delay and percentage of patients with longer patient delay

Average number of health care provider encounters before diagnosis and percentage of patients who encountered $\geq 2$ non-TB health providers

Percentage of patients with first non-TB health contact following onset of TB symptoms

\section{Importance \\ Median Mode CV Consensus}

(\% score of $>7$ )

Feasibility

Median Mode CV Consensus

(\% score of $>7$ )

\section{TB patients}

\section{Domain}

Adherence to treatment

Isolation behaviors during period of infection

\section{Subdomain}

Adhere to medication

Follow-up sputum microscopy

Changing unhealthy lifestyle

Disposal of sputum

Wearing respirator in public during infective phase of disease

Behaviors related to using separate utensils (spoons, plates, forks and chopsticks)

Isolation room

Room ventilation

\section{Indicators}

Percentage of patients who adhered to their medication

Percentage of patients who missed dose

Percentage of patients with interrupted treatment

Percentage of patients with default treatment

Percentage of patients who kept follow-up sputum microscopy appointment

Percentage of patients who abstained from smoking

Percentage of patients who abstained from alcohol drinking

\begin{abstract}
9
\end{abstract}
9

9

9

$9 \quad 0.1$

0.1

93.8

100

100

100

75.1

93.8

$9 \quad 0.2$

9.

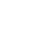

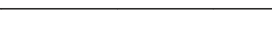

$(\%$


Table 3 Results of round-1 survey (Continued)

\begin{tabular}{lllllllll}
\hline Percentage of patients who used dishes and chopsticks separately & 5 & 5 & 0.5 & 43.8 & 9 & 9 & 0.2 & 75.1 \\
Percentage of patients with isolation room & 7 & 7 & 0.2 & 75 & 7 & 9 & 0.4 & 56.3 \\
Percentage of patients who often ventilated room & 9 & 9 & 0.1 & 100 & 9 & 9.2 & 87.6 \\
\hline
\end{tabular}

Note: $\mathrm{CV}$ refers to Coefficient of variation.

TB control and prevention, which clearly qualifies them to evaluate indicators (Table 2).

\section{Results of round-1 survey}

Results of round 1 Delphi survey of the experts are shown in Table 3. Based on rankings for importance and feasibility for the framework for TB-suspect by experts, median scores ranged from 7 to 9 , and CVs were less than 0.3 (Table 3). Those results indicated that expert rankings had good central tendencies for all items in terms of indicator's importance and feasibility.

For the TB patients, medians and modes for the importance were 7 or 9 and $\mathrm{CVs}$ for the importance were lest 0.3 except for two items ("Behaviors related to deal with dishes", and "Percentage of patients who used dishes and chopsticks separately"). However, the median for feasibility rankings of 6 items and mode for feasibility rankings of 5 items were 5 ; CVs for feasibility rankings of 12 items were more than 0.3 (Table 3). These results indicated that expert rankings had good central tendencies for most items in terms of importance, but not for the feasibility.

\section{Indicator screening after first-round survey}

Based on criteria for the consensus as earlier stated, indicators with a consensus score of $>7$ by $>70 \%$ of the experts were considered as appropriate indicators and indicators with a consensus score of $\leq 5$ by $>70 \%$ of experts were excluded. Table 3 shows that for TB suspects, inclusion consensus was reached after round-1 survey on: one domain ("Health-care seeking behavior"), two sub-domains ("Care seeking behavior at onset of TB symptoms" and "Care-seeking pathways") and two indicators ("Average number of health care provider encounters before diagnosis and percentage of patients who encountered $\geq 2$ non-TB health providers" and "Percentage of patients with first non-TB health contact following onset of TB symptoms").

For TB patients, consensus was reached on: one domain ("Adherence to treatment"), two sub-domains ("Adherence to their medication" and "Follow-up sputum microscopy"), and four indicators ("Percentage of patients who adhere to their medication", "Percentage of patients who missed dose", "Percentage of patients who kept follow-up sputum microscopy" and "Percentage of patients who often ventilated room").
Regarding the indicators for TB suspects, experts did not suggest deleting any item; two indicators ("Period of patient delay and percentage of patients with longer patient delay" and "Average number of health care provider encounters before diagnosis and percentage of patients who encountered $\geq 2$ health providers") were suggested to be separated into two indicators for each; five new items (1 domain, 1 subdomain and 3 indicators) were suggested to be added to the questionnaire (Additional file 1: Table S4). Finally, 2 domains, 3 subdomains, and 8 indicators were included in the questionnaire for the second-round survey (Table 3).

As for indicators for TB patients, experts in the firstround survey suggested the deletion of: 4 subdomains ("Change unhealthy lifestyle", "Wearing respirator in intensive phrase in public", "Behaviors related to deal with dishes", and "Isolation room"), and 2 indicators ("Percentage of patients who used dishes and chopsticks separately" and "Percentage of patients who had separate living room from others in household"). One item in the domain was modified ("Isolation behaviors" was changed into "Transmission prevention"). They also suggested the inclusion of eight new items to the questionnaire, including 1 domain, 4 sub-domains, and 3 indicators (Additional file 1: Table S4). Finally, 3 domains, 8 sub-domains, and 15 indicators were included in the questionnaire for the second-round survey (Table 3).

\section{Results of second survey}

According to the rankings in the round-2 survey, items in the questionnaire for both TB suspects and TB patients were very important and feasible (median or mode for importance and feasibility for all indicators ranged from 7 to 9, CVs for all indicators were less than 0.3) (Table 4). These results indicated that expert rankings in the second round survey had good central tendency for most of the items in terms of importance and feasibility for both TB suspects and TB patients.

\section{Framework of indicators for behavioral outcome assessment of TB health promotion for TB suspects and patients}

The following results are based on our criteria for inclusion and exclusion consensus. Regarding indicators for TB suspects, consensus was achieved for importance and 
Table 4 Results of round 2 survey

\begin{tabular}{|c|c|c|c|c|c|c|c|c|}
\hline \multirow[t]{2}{*}{ Item } & \multicolumn{4}{|c|}{ Importance } & \multicolumn{4}{|c|}{ Feasibility } \\
\hline & Median & Mode & $\mathrm{CV}$ & $\begin{array}{c}\text { Consensus } \\
(\% \text { score of }>7)\end{array}$ & Median & Mode & $\mathrm{CV}$ & $\begin{array}{c}\text { Consensus } \\
(\% \text { score of }>7)\end{array}$ \\
\hline
\end{tabular}

\section{TB suspect}

Domain

Healthcare seeking behavior

Transmission prevention

$\begin{array}{cccccccc}9 & 9 & 0.1 & 100 & 7 & 7 & 0.1 & 100 \\ 9 & 9 & 0.1 & 100 & 7 & 7 & 0.2 & 68.8 \\ 9 & 9 & 0.0 & 100 & 9 & 9 & 0.1 & 100 \\ 9 & 9 & 0.1 & 100 & 7 & 7 & 0.1 & 93.8 \\ 9 & 9 & 0.2 & 93.7 & 7 & 7 & 0.4 & 56.3 \\ & & & & & & & \\ 9 & 9 & 0.1 & 100 & 7 & 9 & 0.2 & 87.6 \\ 9 & 9 & 0.1 & 100 & 7 & 9 & 0.2 & 87.6 \\ 7 & 7 & 0.2 & 87.6 & 8 & 9 & 0.2 & 81.3 \\ 7 & 7 & 0.2 & 87.6 & 8 & 9 & 0.2 & 81.3 \\ 9 & 9 & 0.1 & 100 & 9 & 9 & 0.2 & 87.6 \\ 7 & 9 & 0.2 & 81.3 & 7 & 9 & 0.2 & 75.1 \\ 9 & 9 & 0.2 & 93.7 & 7 & 7 & 0.3 & 81.3 \\ 9 & 9 & 0.1 & 100 & 7 & 7 & 0.3 & 75\end{array}$

Subdomain

Seeking care after onset of TB symptom

Pathways of seeking care

Interpersonal contact etiquette

Indicator

Length of patient delay and

Percentage of patients with longer patient delay

Number of health care provider encounters before diagnosis, and

Percentage of patients who encountered $\geq 2$ non-TB

health providers

Percentage of patients with first non-TB health contact following onset of TB symptoms

Percentage of patients who wore respirator in public during in infective phrase of disease

Percentage of patients who consistently abstained from spitting

Percentage of patients who covered face when sneezing/cough/speaking loudly

\section{TB patient}

\section{Domain}

Adherence to treatment

Healthy lifestyle

Transmission prevention

\section{Subdomain}

Adhere to medication

Follow-up sputum microscopy

Abstinence from smoking

Abstinence from alcohol drinking

Nutrition improvement

Disposal of sputum

Interpersonal contact etiquette

Room ventilation

\section{Indicator}

Percentage of patients who adhered to their medication

Percentage of patients who missed dose of drugs

Percentage of patients with interrupted treatment

Percentage of patients with default treatment

Percentage of patients who kept follow-up sputum microscopy

Percentage of patients who abstained from smoking

Percentage of patients who abstained from alcohol drinking

Percentage of patients who improved nutrition

ran

$\begin{array}{llll}9 & 9 & 0.0 & 100 \\ 9 & 9 & 0.2 & 100 \\ 9 & 9 & 0.1 & 93.7\end{array}$

100

93.7

100

68.8

75

100

100

81.3

75.1

73.4

81.3

68.8

98.7

100

93.7

93.7

100

100

100

81.3

75.1

73.4 
Table 4 Results of round 2 survey (Continued)

\begin{tabular}{|c|c|c|c|c|c|c|c|c|}
\hline Percentage of patients who consistently abstained from spitting & 9 & 9 & 0.1 & 100 & 7 & 9 & 0.2 & 81.3 \\
\hline Percentage of patients with safe method of sputum disposal & 9 & 9 & 0.2 & 93.3 & 9 & 9 & 0.2 & 86.6 \\
\hline $\begin{array}{l}\text { Percentage of patients who covered face when } \\
\text { sneezing/cough/speaking loudly }\end{array}$ & 9 & 9 & 0.1 & 100 & 7 & 9 & 0.2 & 75.1 \\
\hline $\begin{array}{l}\text { Percentage of patients who wore respirator in public during } \\
\text { in infective phrase of disease }\end{array}$ & 9 & 9 & 0.2 & 87.6 & 7 & 7 & 0.3 & 62.5 \\
\hline $\begin{array}{l}\text { Percentage of patients who reduced frequency of presence } \\
\text { in public }\end{array}$ & 8 & 9 & 0.2 & 68.8 & 7 & 7 & 0.2 & 62.6 \\
\hline Percentage of patients who informed contact of TB status & 8 & 9 & 0.1 & 100 & 7 & 9 & 0.2 & 100 \\
\hline Percentage of patients who ventilated their room & 9 & 9 & 0 & 100 & 9 & 9 & 0.1 & 100 \\
\hline
\end{tabular}

Note: $\mathrm{CV}$ refers to Coefficient of variation.

feasibility except the feasibility of one domain ("Transmission prevention", scored $\geq 7$ by $68.8 \%$ ) and one subdomain ("Interpersonal contact etiquette", scored $\geq 7$ by $56.3 \%$ ) (Table 4). For TB patients, only one indicator ("Percentage of patients who reduced frequency of presence in public") was scored $\geq 7$ by $<70 \%$ participants for both importance and feasibility (68.8\% and 62.6\%). Consensus was achieved on importance of the rest items and on feasibility of most items except for one domain ("Healthy lifestyle", scored $\geq 7$ by $68.8 \%$ ), one subdomain ("Interpersonal contact etiquette", scored $\geq 756.3 \%$ ), and one indicator ("Percentage of patients who wear respirators in public", scored $\geq 762.5 \%$ ) (Table 4).

We organized a round-table discussion for TB control experts to decide on final items for the framework. Following this discussion, 2 domains, 3 subdomains, and 8 indicators emerged for TB suspects. There 3 domains, 8 subdomains, and 14 indicators emerged for TB patients (Table 5). In addition, we provided definitions related to the indicators in Additional file 1: Table S5.

\section{Discussion}

Health promotion has the capacity to address most of the TB prevention and care challenges at the individual, societal, and health systems levels. However, to demonstrate the utility of health promotion in efforts to reduce the global burden of TB, appropriate indicators which can facilitate evaluation of its outcomes are urgently needed. Although there are compendiums of indicators for assessing interventions to address such other major infectious diseases of global significance as HIV/AIDS [32,33], there are currently no validated indicators to guide implementation and evaluation of behavioral interventions to reduce TB. In an attempt to address this gap in knowledge and practice, we embarked on the development of such a compendium of behavioral indicators for TB health promotion interventions, using the Delphi method, which has been widely applied in diverse areas of population health [67,71].

Participants in the Delphi surveys and discussions were TB control experts with extensive field experience.
The authority coefficient was 0.91 in the first-round Delphi survey and 0.92 in the second-round survey, which indicated a high degree of authority in the field of TB control of the experts in the Delphi surveys, and which qualified them for participation in the survey.

The Delphi process benefitted from the use of a survey instrument that was developed following a systematic review of the global TB control literature [11,47-60], review of government TB control program documents [28], local and international expert consultations. According to documents review, one of the behavioral goals of TB health promotion is to encourage TB suspects to seek healthcare in a timely manner, and to adhere to treatment and management of their disease $[15,28,55]$. Consequently, the conceptual framework proposed in this study included 1 domain ("Healthcare seeking behavior"), 2 sub-domains ("Seeking care after onset of TB symptoms" and "Pathways of seeking care") and 5 indicators (including among other, "Length of patient delay") to evaluate the healthcare seeking behaviors for TB suspects. To evaluate health promotion activities that target behaviors related to adherence to treatment for TB patients, the proposed framework included 1 domain ("Adherence to treatment"), 2 subdomains ("Adherence to medication" and "Follow-up sputum microscopy") and 4 indicators (including among other, "Percentage of patients who adhered to their medication").

$\mathrm{TB}$ is a communicable disease that spreads through the air. If untreated, each patient with active TB can on average, infect 10 to 15 people every year [72]. It is therefore, important for TB suspects and patients to adopt behaviors that discourage transmission of the infection to others through TB health promotion $[15,55]$. Thus, in order to evaluate outcome of TB health promotion in TB prevention, this study proposed a framework that includes for TB suspects, 1 domain ("Transmission prevention"), 1 sub-domain ("Interpersonal contact etiquette") and 3 indicators (including among others, "Percentage of patients who wore respirator in Public"). The framework for TB patients includes 1 domain ("Transmission prevention"), 2 sub-domains ("Interpersonal contact etiquette" and 
Table 5 Framework of indicators

Domain Subdomains

Indicators

Measures

\section{Data source}

$T B$ suspects

Healthcare

Seeking care after

Length of patient delay

Mean, median and range of patient delay

seeking behavior onset of TB symptoms

Pathways of seeking care Average number of health care provider

Percentage of patients with longer

patient delay

encounters before diagnosis

Percentage of patients who encountered $\geq 2$ non-TB health providers

Percentage of patients with first non-TB health contact following onset of TB symptoms

Transmission Interpersonal contac prevention etiquette

Percentage of patients who wore respirator in Public

Percentage of patients who consistently abstained from spitting

Percentage of patients who consistently covered face when sneezing/cough/speaking loudly

\section{TB patients}

Adherence to treatment

Adherence to medication

Percentage of patients who adhered to medication

Percentage of patients with interrupted treatment

Percentage of patients with default treatment

Follow-up sputum microscopy

Healthy lifestyle

Abstinence from smoking

Abstinence from alcohol drinking

Nutrition improvement

Transmission prevention

Disposal of sputum

Interpersonal contact etiquette
Percentage of patients who kept follow-up sputum microscopy

from smoking

Percentage of patients who abstained from alcohol drinking

Percentage of patients with improved nutritional status

Percentage of patients who consistently abstained from spitting

Percentage of patients with safe method

Percentage of patients who covered face when sneezing/cough/speaking loudly of sputum disposal
Percentage of patients with longer delay

Average number of health care provider encounters before diagnosis

Percentage of patients who encountered $\geq 2$

non-TB health providers

Percentage of TB suspects who had first provider contact in non-TB health facility after onset of TB symptoms

Percentage of patients who wore respirator in Public after onset of TB symptoms

Percentage of patients who consistently abstained from spitting after onset of TB symptoms

Percentage of patients who consistently covered face when sneezing/cough/speaking loudly

Percentage of patients who adhered to their medication

Percentage of patients who experienced interrupted treatment.

Percentage of patients who experienced default treatment Percentage of patients who kept follow-up sputum microscopy at the end of 2,5 and 6 month of treatment Percentage of patients who abstained from smoking following TB health promotion.

Percentage of patients who abstained from drinking alcohol following TB health promotion.

Percentage of patients with improved nutritional status (e.g., assessed through weight or other anthropometric measures) following TB health promotion.

Percentage of patients who consistently abstained from spitting sputum after diagnosis with TB

Percentage of patients with safe method of sputum

Percentage of patients who consistently covered face among ten times of sneezing/cough/ speaking loudly disposal during the infective phrase of disease
B suspect survey and clinic record review to learn the time of TB symptoms onset and the time for seeking care for first time

TB suspect survey and clinic record

TB suspect survey and clinic record

TB suspect survey and clinic record

TB suspect survey and clinic record

TB suspect survey

TB suspect survey

TB suspect survey

TB patient survey and clinic record review

TB patient survey and clinic record review

TB patient survey and clinic record review

TB patient survey or and clinic record review

TB patient survey

TB patient survey

TB patient survey

TB patient survey

TB patient survey

TB patient survey 
Table 5 Framework of indicators (Continued)

\begin{tabular}{|c|c|c|c|}
\hline & $\begin{array}{l}\text { Percentage of patients who wore respirator in } \\
\text { public during in infective phrase of disease }\end{array}$ & $\begin{array}{l}\text { Percentage of patients who consistently } \\
\text { wore respirator in public after diagnosis of TB }\end{array}$ & TB patient survey \\
\hline & $\begin{array}{l}\text { Percentage of patients who reduced } \\
\text { frequency of presence in public }\end{array}$ & $\begin{array}{l}\text { Percentage of patients who reduce times spent } \\
\text { in public places }\end{array}$ & TB patient survey \\
\hline & $\begin{array}{l}\text { Percentage of patients who informed } \\
\text { contact of TB status }\end{array}$ & $\begin{array}{l}\text { Percentage of patients who disclosed their TB infection } \\
\text { to their contacts and informed them to screen for TB }\end{array}$ & $\begin{array}{l}\text { TB patient survey and clinic record } \\
\text { review about contact screening }\end{array}$ \\
\hline Room ventilation & $\begin{array}{l}\text { Percentage of patients who ventilated } \\
\text { their room }\end{array}$ & $\begin{array}{l}\text { Percentage of patients who often ventilated their } \\
\text { living room }\end{array}$ & TB patient survey \\
\hline
\end{tabular}


"Room ventilation") and 5 indicators (including among others, "Percentage of patients who consistently covered their mouth/nose when sneezing/cough/speaking loudly").

Although TB health promotion primarily aims to encourage patients to adhere to their treatment, WHO documents also emphasized that efforts should be made to cover a wider range of health related behaviors that help to prevent and cure TB, such as improved nutrition, avoidance of smoking, abstinence from alcohol use, as well as behaviors that prevent TB $[15,55]$. Evidences from the literature shows that smoking, use of alcohol and poor nutrition are associated with poor TB treatment outcome [53,54]. Therefore, for TB patients, the proposed framework includes 1 domain (Healthy lifestyle), 3 subdomains ("Abstaining from smoking", "Abstaining from alcohol drinking" and "Nutrition improvement") and 3 indicators ("Percentage of patients who abstained from smoking", "Percentage of patients who abstained from alcohol drinking" and "Percentage of patients who improved nutrition").

\section{Strengthens and limitations}

This study fills an important void in efforts to control TB globally by suggesting benchmarks that TB control programs around the world, which could adopt in their assessment of outcomes of their efforts. In the face of scarcity of resources, and considering that every resource spent on TB health promotion has opportunity costs in other sectors of any country's economy, it is important to determine whether TB health promotion efforts are making an impact. This is critical in determining if resources are being spent judiciously or whether the resource should be spent on alternative strategies of proven effectiveness.

The Delphi process adopted in this study employed strict quality control measures. Local and international TB control experts were consulted in the design and implementation of the Delphi surveys. The expert panel consisted of professionals from thirteen provinces of China and demonstrated a high authority coefficient. Most experts had leading positions within their institutions in addition to extensive experience in TB control. Due to the multiple feedback processes inherent in the Delphi process, the potential low response rates, and striving to maintain robust feedback can be a challenge [59]. However, the return rates for this study were high at $94.1 \%$ and $100 \%$ for round 1 and 2 surveys, respectively.

Although the experts achieved high consensus on the domains, sub-domains and indicators, it is important to note that the extent to which participants agree with each other does not necessarily mean that the "correct" answer has been found [56]. Thus, there is the danger of over reliance on the final results without acknowledging the influence of bias and other factors on validity and reliability [56]. Further validation of the identified indicators by other national and global TB control programs is therefore warranted. It is also important to note that as a qualitative research method, Delphi studies do not, and are not intended to, produce statistically significant results. Rather, the results represent a synthesis of the opinions of the particular group involved in the process [73]. Thus, findings from this Delphi survey represent an important starting point for debate and consensus on global indicators for assessing the effectiveness of TB behavioral health promotion programs. The involvement of more experts and TB control programs from other parts of the globe will increase validity and reliability of the results [58]. To enhance generalizability, a number of strategies can be used: focus groups can be integrated or comparisons can be made with sub-domain-validated data [56]. A quasiexperimental design can be used as a follow-up method to test the results of the Delphi process [61], and a "consensus conference" can be organized to discuss the validity of the Delphi results. Finally, as noted in Table 5, much of the evaluation data for the proposed framework of indicators would rely on reports from patients and suspects. Since self-reports are known to be subject to social desirability, it is important that evaluation strategies for $\mathrm{TB}$ health promotion include good quality control and mixedmethod approaches that seek to reduce bias and increase data quality.

\section{Conclusion and implications}

This investigation proposes a framework of primary behavioral indicators for evaluation of TB health promotion programs. The results provide a basis for further research. Before any performance indicator can be adopted, it needs to be clearly defined and tested for reliability, validity, and responsiveness (the ability to detect a significant change in performance). Therefore, further studies are needed to validate the indicators in diverse settings. In spite of the need for further study, the proposed framework of TB behavioral health promotion indicators can be used to more comprehensively monitor, evaluate, and improve the quality of TB health promotion programs by health practitioners and policy makers.

\section{Additional file}

Additional file 1: Table S1. Items in the questionnaires of round Delphi survey. Table S2. Quantification of judgment criterion. Table S3. Quantification of the level of familiarity. Table S4. Indicators changes after first round survey. Table S5. Definitions of indicators.

\section{Abbreviations}

MDR-TB: Multi-drug resistant TB; HIV/AIDS: Human immunodeficiency virus infection/acquired immunodeficiency syndrome; SPSS: Statistical package for the social sciences; CV: Coefficient of variation; SD: Standard deviation; WHO: World Health Organization. 


\section{Competing interests}

The authors declare that they have no competing interests.

\section{Authors' contributions}

$Y L$ designed the study. $\mathrm{DH}$ and $\mathrm{YL}$ designed the instrument for data collection and organized expert discussion; $Y L$ and $Y Z$ organized and analyzed data; $D H$, and JC contacted the experts for Delphi survey. YL and JE drafted the manuscript. JE revised and edited the manuscript. All authors interpreted the results, commented on the report, and approved the final version.

\section{Acknowledgement}

This project was funded by the National Natural Science Foundation of China (Award \# 81001297). The authors would like to thank participants in the expert panels and discussions for their valuable input to the development of the proposed frameworks. The authors also thank Professor Shenglan Tang at Duke University Medical School, Durham, NC, USA, for his comments on earlier draft of this paper.

\section{Author details}

${ }^{1}$ Department of Social Medicine and Health Service Management, Third Military Medical University, No.30 Gaotanyan Road, Shapingba district, Chongqing 400038, China. ${ }^{2}$ Division of Health Promotion Sciences/Global Health Institute, Mel \& Enid Zuckerman College of Public Health, University of Arizona, Tucson, Arizona, USA. ${ }^{3}$ Chongqing Institute of TB Prevention and Treatment, Jiulongpo district, Chongqing, China. ${ }^{4}$ Department of Health statistics, College of Preventive Medicine, Third Military Medical University, Chongqing, China. ${ }^{5}$ College of Preventive Medicine, Key Lab of Medical Protection for Electromagnetic Radiation, Ministry of Education of China, Third Military Medical University, Chongqing, China.

Received: 30 August 2013 Accepted: 6 May 2014

Published: 16 May 2014

\section{References}

1. WHO: Global tuberculosis report 2012. [http://www.who.int/tb/publications/ global_report/gtbr12_main.pdf]

2. Bolotin S, Alexander DC, Guthrie JL, Drews SJ, Jamieson F: The Ontario universal typing of tuberculosis (OUT-TB) surveillance program-what it means to you. Can Respir J 2010, 17:e51-e54.

3. Ngadaya ES, Mfinanga GS, Wandwalo ER, Morkve O: Delay in tuberculosis case detection in Pwani region Tanzania. A cross sectional study. BMC Health Serv Res 2009, 9:196.

4. Selvam JM, Wares F, Perumal M, Gopi PG, Sudha G, Chandrasekaran V, Santha T: Health-seeking behavior of new smear-positive TB patients under a DOTS programme in Tamil Nadu, India, 2003. Int J Tuberc Lung Dis 2007, 11:161-167.

5. Zhang QG: Factors associated with delayed identification of PTB. Anthol Med 2006, 25:655-657.

6. Demissie M, Lindtjorn B, Berhane $Y$ : Patient and health service delay in the diagnosis of pulmonary tuberculosis in Ethiopia. BMC Public Health 2002, 2:23.

7. Sendagire I, Schim Van der Loeff M, Mubiru M, Konde-Lule J, Cobelens F: Long delays and missed opportunities in diagnosing smear-positive pulmonary tuberculosis in Kampala, Uganda: a cross-sectional study. PLoS One 2010, 5:e14459.

8. Storla DG, Yimer S, Bjune GA: A systematic review of delay in the diagnosis and treatment of tuberculosis. BMC Public Health 2008, 8:15.

9. Sreeramareddy $C T$, Panduru KV, Menten J, Van den Ende J: Time delays in diagnosis of pulmonary tuberculosis: a systematic review of literature. BMC Infect Dis 2009, 9:91.

10. Johnston JC, Shahidi NC, Sadatsafavi M, Fitzgerald JM: Treatment outcomes of multidrug-resistant tuberculosis: a systematic review and meta-analysis. PLoS One 2009, 4:e6914.

11. Li Y, Ehiri J, Tang S, Li D, Bian Y, Lin H, Marshall C, Cao J: Factors associated with patient, and diagnostic delays in Chinese TB patients: a systematic review and meta-analysis. BMC Med 2013, 11:156.

12. Brasil PE, Braga JU: Meta-analysis of factors related to health services that predict treatment default by tuberculosis patients. Cad Saude Publica 2008, 24:s485-s502.
13. Munro SA, Lewin SA, Smith HJ, Engel ME, Fretheim A, Volmink J: Patient adherence to tuberculosis treatment: a systematic review of qualitative research. PLoS Med 2007, 4:e238.

14. Orenstein EW, Basu S, Shah NS, Andrews JR, Friedland GH, Moll AP, Gandhi NR, Galvani AP: Treatment outcomes among patients with multidrug-resistant tuberculosis: systematic review and meta-analysis. Lancet Infect Dis 2009, 9:153-161.

15. Health promotion: The Ottawa Charter for Health Promotion. In Ottawa: First International Conference on Health Promotion; 1986 [http://www.who. int/healthpromotion/conferences/previous/ottawa/en/index1.html]

16. Margot ML: Health promotion and health education. In Guidelines for Tuberculosis control in New Zealand 2003. [http://www.moh.govt.nz/ notebook/nbbooks.nsf/0/ab73cdededa23595cc2577a0006b7e38/\$FILE/ TBControlGuidelines03.pdf]

17. WHO: Mainstreaming Health Promotion - a Practical Toolkit. In Prepared for the 7th global conference for health promotion: 'Promoting Health and Development, Closing the Implementation Gap', 26th-30 th October 2009. 2009 [http://gchp7.info/resources/downloads/toolkit.pdf]

18. He GX, Zhou L, Xu M, Cheng SM: Implementing DOTS strategy through tuberculosis clubs. Int J Tuberc Lung Dis 2005, 9:S135-S136.

19. Harries A, Kenyon T, Maher D, Floyd K, Nyarko E, Nkhoma W: Community TB care in Africa": a collaborative project coordinated by WHO. In Report on a "lessons learned" meeting in Harare, Zimbabwe, 27-29 September 2000. [http://whqlibdoc.who.int/hq/2001/WHO_CDS_TB_2001.291.pdf]

20. Allen S, Dick J: The potential of brief motivational interviewing to enhance tuberculosis care. Int J Tuberc Lung Dis 2003, 7:S190-S191.

21. Macq J, Torfoss T, Getahun H: Patient empowerment in tuberculosis control: reflecting on past documented experiences. Trop Med Int Health 2007, 12:873-885.

22. Akramul I: Community participation in TB control as part of social development: the experience of BRAC. Int J Tuberc Lung Dis 2005, 9:0S37.

23. Alvarze Gordillo Gdel C, Alvarez Gordillo JF, Dorantes Jiménez JE: Educational strategy for improving patient compliance with the tuberculosis treatment regimen in Chiapas, Mexico. Rev Panam Salud Publica 2003, 14:402-408.

24. Rangan S, Gupte H, Bandiwadekar A, Ambe G: Tackling tuberculosis in urban areas: experiences from Mumbai city. Health Admin 2003, XV:72-79.

25. Cass AD, Talavera GA, Gresham LS, Moser KS, Joy W: Structured behavioral intervention to increase children's adherence to treatment for latent tuberculosis infection. Int J Tuberc Lung Dis 2005, 9:415-420.

26. Franks J, Colson P, Hirsch-Moverman Y, Charles P: Adherence to Treatment for Latent Tuberculosis Infection: A Manual for Health Care Providers. New York: Felton National Tuberculosis Center; 2005.

27. Department of Disease Control of Ministry of Health: Guideline on Enforcement of Chinese Tuberculosis Control Program. Beijing, China: Ministry of Health; 2006:11. Edition for Suggestion.

28. Department of Disease Control of Ministry of Health: Guideline on Enforcement of Chinese Tuberculosis Control Program. Beijing, China: Ministry of Health; 2008.

29. Rossi P, Freeman H: Evaluation: a systematic approach. Newbury Park, CA: Sage Publications; 1993.

30. Moskowitz J: Preliminary Guidelines for Reporting Outcome Evaluation Studies of Health Promotion and Disease Prevention Programs. In Evaluating Health Promotion Programs. Edited by Braverman MT. San Francisco, Calif: Jossey-Bass; 1989.

31. Thorogood M, Coombes Y (Eds): Evaluating Health Promotion: Practice and Methods. Oxford: Oxford University Press; 2000.

32. World Health Organization: National AIDS programmes: a guide to indicators for monitoring and evaluating national HIV/AIDS prevention programmes for young people. In ISBN 924159257 5. 2004 [http://www. who.int/hiv/pub/epidemiology/napyoungpeople.pdf]

33. National AIDS programme: A guide to monitoring and evaluation. In Geneva: Joint United Nations Programme on HIV/AIDS (UNAIDS), 2000 (UNAIDS/00.17E); [http://www.who.int/hiv/pub/epidemiology/en/JC427Mon_Ev-Full_en.pdf?ua=1]

34. WHO: Global Strategy on Diet, Physical Activity and Health: A framework to monitor and evaluate implementation. [http://www.who.int/ dietphysicalactivity/Indicators\%20English.pdf]

35. WHO: Compendium of Indicators for Monitoring and Evaluating National TB Programmes. [http://whqlibdoc.who.int/hq/2004/ WHO_HTM_TB_2004.344.pdf] 
36. WHO: Toman's Tuberculosis Case Detection, Treatment, and Monitoring 2nd edition. Geneva: WHO; 2004.

37. WHO: Who report 2005 global TB control surveillance, planning, financing. 2005

38. Ajzen I: The Theory of Planned Behavior. Organ Behav Hum Decis Process 1991, 50:179-211.

39. Prochaska J, Johnson S, Lee P: The transtheoretical model of behavior change. In The Handbook of Health Behavior Change. 2nd edition. Edited by Schumaker S, Schron E, Ockene J, McBee W. New York, NY: Springer; 1998.

40. Harrison JA, Mullen PD, Green LW: A meta-analysis of studies of the Health Belief Model with adults. Health Educ Res 1992, 7:107-116.

41. Ospina MB, Bond K, Schull M, Innes G, Blitz S, Rowe BH: Key indicators of overcrowding in Canadian emergency departments: a Delphi study. CJEM 2007, 9:339-346.

42. Linstone HA, Turoff M: The Delphi Method: Techniques and Applications. In 2002 [http://is.njit.edu/pubs/delphibook]

43. Dalkey NC: The Delphi Method: An Experimental Study of Group Opinion. In 1969 [http://www.rand.org/content/dam/rand/pubs/ research_memoranda/RM5888/RM5888.pdf]

44. Green KC, Armstrong JS, Graefe A: Methods to Elicit Forecasts from Groups: Delphi and Prediction Markets Compared. Foresight: Internat J Appl Forecasting 2007, 8:17-21.

45. Häder M: Delphi Befragungen - Ein Arbeitsbuch (Delphi surveys) Westdeutscher Verlag GmbH: Wiesbaden, Germany; 2002

46. Maxwell J: Designing a qualitative study. In Handbook of applied social research methods. Edited by Bickman L, Rog DJ. Thousand Oaks, CA: Sage; 1997:69-100.

47. Pronyk RM, Makhubele MB, Hargreaves JR, Tollman SM, Hausler HP: Assessing health seeking behavior among tuberculosis patients in rural South Africa. Int J Tuberc Lung Dis 2001, 5:619-627.

48. Wang W, Jiang Q, Abdullah AS, Xu B: Barriers in accessing to tuberculosis care among non-residents in Shanghai: a descriptive study of delays in diagnosis. Eur J Public Health 2007, 17:419-423.

49. Bai LQ, Xiao SY: Factors associated with diagnostic delay for patients with smear-positive pulmonary tuberculosis in rural Hunan, China. Zhonghua Jie He He Hu Xi Za Zhi 2004, 27:617-620.

50. Maamari F: Case-finding tuberculosis patients: diagnostic and treatment delays and their determinants. East Mediterr Health J 2008, 14:531-545.

51. Cambanis A, Ramsay A, Yassin MA, Cuevas LE: Duration and associated factors of patient delay during tuberculosis screening in rural Cameroon. Trop Med Int Health 2007, 12:1309-1314

52. Zerbini E, Chirico MC, Salvadores B, Amigot B, Estrada S, Algorry G: Delay in tuberculosis diagnosis and treatment in four provinces of Argentina. Int $J$ Tuberc Lung Dis 2008, 12:63-68.

53. dos Santos MA, Albuquerque MF, Ximenes RA, Lucena-Silva NL, Braga C, Campelo AR, Dantas OM, Montarroyos UR, Souza WV, Kawasaki AM, Rodrigues $L C$ : Risk factors for treatment delay in pulmonary tuberculosis in Recife. Brazil BMC Public Health 2005, 5:25.

54. Papathakis P, Piwoz E: Nutrition and Tuberculosis: A Review of the Literature and Considerations for TB Control Programs. In United States Agency for International Development, Africa's Health 2010 Project. 2008:1-45. [http://digitalcommons.calpoly.edu/cgi/viewcontent.cgi? article $=1009 \&$ context $=f$ sn_fac $]$

55. WHO \& IUATLD: A WHO/The Union monograph on TB and tobacco control. Joining efforts to control two related global epidemics. World Health Organization \& International Union Against Tuberculosis and Lung Disease; 2007 [http://www.who.int/tobacco/resources/publications/ tb_tobac_monograph.pdf]

56. Brown B: Delphi Process: A methodology using for the elicitation of opinions of experts. Rand Corporat 1987, 9:3925.

57. Hasson F, Keeney S, McKenna H: Research guidelines for the Delphi survey technique. J Adv Nurs 2000, 32:1008-1015.

58. Keeney $\mathrm{S}$, Hasson F, McKenna $\mathrm{H}$ : Consulting the oracle: ten lessons from using the Delphi technique in nursing research. J Adv Nurs 2006, 53:205-212.

59. Mitchell W: The Delphi technique: An exposition and application. Technology Analysis \& StPercentage of patientsgic Management 1991, 3:333-358.

60. Hsu CC, Sandford BA: The Delphi technique: making sense of consensus. Pract Assess Res Eval 2007, 12:1-8.

61. Loughlin KG, Moore LF: Using Delphi to achieve congruent objectives and activities in a paediatrics department. J Med Educ 1979, 54:101-106.
62. McKenna H, Hasson F, Smith M: A Delphi survey of midwives and midwifery students to identify non-midwifery duties. Midwifery 2002 18:314-322.

63. Mcllrath C, Keeney S, McKenna H, McLaughlin D: Benchmarks for effective primary care-based nursing services for adults with depression: a Delphi study. J Adv Nurs 2010, 66:269-281.

64. Green B, Jones M, Hughes D, Williams A: Applying the Delphi technique in a study of GPs information requirements. Health Soc Care Community 1999, 7:198-205.

65. Green PJ: The content of a college-level outdoor leadership course. Spokane, WA: Paper presented at the Conference of the Northwest District Association for the American Alliance for Health, Physical Education, Recreation, and Dance; 1982.

66. Grobbelaar SS: Data gathering: Delphi method. R\&D in the National system of Innovation: system dynamics model. In University of Pretoria etd; 2007. (Doctoral Thesis) [http://upetd.up.ac.za/thesis/available/etd07212007-130132/unrestricted/00front.pdf]

67. Cantrill JA, Sibbald B, Buetow S: Indicators of the appropriateness of long-term prescribing in general practice in the United Kingdom: consensus development, face and content validity, feasibility, and reliability. Qual Health Care 1998, 7:130-135.

68. Beattie E, Mackway-Jones K: A Delphi study to identify performance indicators for emergency medicine. Emerg Med J 2004, 21:47-50.

69. Keeney S, Hasson F, McKenna HP: A critical review of the Delphi technique as a research methodology for nursing. Int J Nurs Stud 2001, 38:195-200.

70. Sema AK, Rafa MK: Terminating Sequential Delphi Survey Data Collection. Pract Assess Res Eval 2012, 17:1-10.

71. de Meyrick J: The Delphi method and health research. Health Educ 2003 $1: 7-16$.

72. WHO: Tuberculosis. [http://www.who.int/mediacentre/factsheets/fs104/en/]

73. Gordon TJ: The Delphi method. Washington, DC: American Council for the United Nations University; 1994. pp. 3-4.

doi:10.1186/1471-2334-14-268

Cite this article as: Li et al:: Framework of behavioral indicators for outcome evaluation of TB health promotion: a Delphi study of TB suspects and Tb patients. BMC Infectious Diseases 2014 14:268.

\section{Submit your next manuscript to BioMed Central and take full advantage of:}

- Convenient online submission

- Thorough peer review

- No space constraints or color figure charges

- Immediate publication on acceptance

- Inclusion in PubMed, CAS, Scopus and Google Scholar

- Research which is freely available for redistribution

Submit your manuscript at www.biomedcentral.com/submit
C Biomed Central 